\title{
Racial Disparities in Health among College Educated African-Americans: Can HBCU Attendance Reduce the Risk of Metabolic Syndrome in Midlife?
}

Cynthia G. Colen, Nicolo P. Pinchak, and Kierra S. Barnett

Correspondence to Dr. Cynthia G. Colen, Department of Sociology, 238 Townshend Hall, 1885

Neil Avenue, Columbus, OH 43210 (email: colen.3@ osu.edu; phone: 614-292-6681; fax: 614292-6687)

Author affiliations:

Department of Sociology, Ohio State University, Columbus, OH (Cynthia G. Colen and Nicolo P. Pinchak); Division of Health Behavior and Health Promotion, College of Public Health, Ohio State University, Columbus, OH (Cynthia G. Colen and Kierra S. Barnett).

Funding:

This research was supported, in part, by P2C-HD058484 from the Eunice Kennedy Shriver National Institute of Child Health \& Human Development (NICHD) awarded to the Ohio State University Institute for Population Research. Pinchak's effort was supported by the National Science Foundation Graduate Research Fellowship Program under Grant No. DGE1255832. Data for this study are from Add Health, a program funded by grant P01-HD31921 (NICHD), with cooperative support from 23 other federal agencies and foundations. The Adolescent Health and Academic Achievement (AHAA) study was funded by grants from NICHD (R01 HD040428-02, Chandra Muller, PI; 5 R24 HD042849, Population Research Center, University of Texas at Austin) and NSF (REC-0126167, Chandra Muller, PI, and Pedro Reyes, Co-PI). The opinions and conclusions expressed herein are solely those of the authors and should not be construed as representing the opinions or policy of any agency of the Federal government.

Conflict of Interest: none declared.

Running head: HBCU Attendance and Health in Midlife 
Abstract:

We expand on existing understandings of health disparities among middle-class AfricanAmericans by examining how the postsecondary educational context gives rise to the unequal distribution of health. We use panel data (1994-2009) from the National Longitudinal Survey of Adolescent to Adult Health (Add Health) to estimate if the risk of developing metabolic syndrome by midlife significantly differs for African-Americans who attended Historically Black College or Universities (HBCUs) vs. predominantly White institutions (PWIs). We find that HBCU enrollment is associated with a 35\% reduction in the odds of metabolic syndrome. Furthermore, we demonstrate that HBCU attendees who grew up in more segregated environments experienced the greatest reductions in the likelihood of developing metabolic syndrome. Our results underscore the important role that HBCUs play in the lives of AfricanAmericans and suggest their impacts go far beyond traditional benchmarks of socioeconomic achievement to include key health outcomes.

Keywords: Health disparities, Educational attainment, African Americans

Abbreviations: Historically Black College or University (HBCU), Predominately White institution (PWI), National Longitudinal Study of Adolescent to Adult Health (Add Health), Integrated Postsecondary Education Data System (IPEDS) 
Racial disparities in health exact a heavy toll on U.S. society, in terms of human life as well as social and economic costs. African-Americans can expect to live 5 fewer years at birth compared to Whites. ${ }^{1}$ Moreover, the years they are alive are often spent living with one or more chronic illnesses or serious disabilities. ${ }^{1,2}$ A robust body of research that seeks to identify the underlying causes of these stark racial disparities in health exists, ${ }^{3}$ however, much remains unknown about the social conditions that give rise to health disparities among Black subpopulations. The current paper seeks to expand our understanding of how health is unequally distributed among African-Americans who attend college in drastically different settings. Specifically, we ask to what extent does enrollment at a Historically Black College or University (HBCU) as opposed to a predominantly White institution (PWI) influence the health of collegeeducated African-Americans.

Despite having relatively high levels of socioeconomic status, the health of middle-class African-Americans lags behind that of similarly situated Whites. In fact, Black/White health disparities are more pronounced among nonpoor subgroups. ${ }^{3}$ One mechanism through which the health of African-Americans is likely to erode over time or "weather" is through exposure to discrimination. ${ }^{4}$ Recent research suggests that upwardly mobile African-Americans are just as likely to experience instances of discrimination as they ascend the socioeconomic hierarchy. ${ }^{5}$ These factors, taken together, indicate that there are specific aspects of the social environment in which middle-class African-Americans live, work, play, and pray that are detrimental to their health. Education is a social exposure that deserves further study to more fully understand why racial disparities in health among middle-class African Americans remain pronounced despite having access to key social and economic resources. 
Education has long been an important predictor of health, so much so that it is considered a fundamental cause of health disparities. ${ }^{6}$ Educational attainment is consistently associated with better health across a wide range of outcomes. ${ }^{7}$ Yet most of what we know about the education/health gradient is limited by a singular focus on completed education as the exposure of interest. Other key aspects of the context in which schooling occurs should be rigorously examined. We argue that in order to more fully understand how education differentially shapes the distribution of morbidity and mortality across race researchers should examine the quality of the educational setting rather than only focusing on the quantity of educational attainment. ${ }^{8}$

For African-Americans, HBCUs provide a unique environment within which learning occurs in predominantly Black spaces. These institutions allow African-American students to pursue educational and occupational goals, develop important life skills, and form lasting friendships while being sheltered, at least somewhat, from racial discrimination. HBCU enrollees are less likely to be the only (or one of a few) African-Americans on campus, thus reducing the harmful health effects of tokenism. ${ }^{9,10}$ Finally, by attending HBCUs, Black students are more likely than their counterparts at PWIs to interact with faculty of color who can serve as mentors, which is particularly advantageous for first-generation college students. ${ }^{11}$

HBCU enrollment has been shown to predict socioeconomic achievement; ${ }^{12,13}$ however, the literature regarding the health effects of HBCU attendance is sparse and much remains unknown due to a primary focus on health behaviors during college as endpoints of interest and a lack of adequate comparison groups of PWI enrollees. ${ }^{14,15}$ The few existing studies that focus on long-term health outcomes provide preliminary evidence that HBCU enrollment is protective for health behaviors or mental health, but do not offer much information regarding physical health. ${ }^{16-18}$ The current study was designed to fill this gap. 
Not only is it important to consider the context in which higher education occurs to accurately assess its role in giving rise to health disparities, it is critical to recognize the importance of the timing during which higher education occurs. Emerging adulthood is the lifecourse period during which the successful "launching" of young adults typically happens. It is when most individuals experience independence from their parents for the first time ${ }^{19}$ and when health behaviors are commonly solidified into lifelong habits. ${ }^{20}$ Peer effects become particularly influential during emerging adulthood as individuals move out of their childhood homes and into shared living arrangements. ${ }^{21}$ Thus, the choice to attend an HBCU rather than a PWI may prove a particularly strong predictor of health across the life course for African-Americans because of when during the lifecourse it occurs.

We also consider if the association between HBCU enrollment and health is more pronounced for individuals who grow up in predominantly Black or White environments. Although racial residential segregation (hereafter: segregation) has been consistently linked to suboptimal health outcomes for African-Americans, ${ }^{22,23}$ it is not clear the extent to which this association is the result of socioeconomic divestment or racial clustering. This is a critical question worth investigating further given that individuals residing in more segregated neighborhoods experience less interpersonal discrimination ${ }^{24}$ and the association between discrimination and health is contingent on the level of neighborhood segregation. ${ }^{25}$

For young African-Americans who spent their formative years in mostly White spaces, attending an HBCU might benefit their health by reducing the frequency of racial discrimination and/or tokenism, both of which have been shown to negatively impact health outcomes. ${ }^{9,10,26,27}$ Alternatively, because predominantly Black schools and neighborhoods are often under resourced, overcrowded, and have less experienced teachers, ${ }^{28,29}$ individuals growing up in these 
environments might benefit, at least with respect to their health, from intraracial connections and mentoring that can be found at HBCUs.

To this end, the current study uses data from the National Longitudinal Survey of Adolescent to Adult Health (Add Health) to answer three specific research questions. First, can African-Americans who attend an HBCU as opposed to a PWI expect to experience better health in adulthood? Second, is the association between HBCU enrollment and adult health largely attributable to early life disadvantage? Third, do the protective health effects of HBCU enrollment differ for African-Americans who grew up in more or less segregated environments?

\section{METHODS}

Add Health is a nationally representative, prospective cohort study of U.S. middle- and highschool students who were in grades 7-12 in 1994-1995 (Wave I). Follow-up interviews were conducted in 1996 (Wave II), 2001 (Wave III), and 2008 (Wave IV). Additional data concerning respondents' schools, neighborhoods, and social networks were collected from school administrators, parents, and friends across multiple waves. Of the total sample surveyed in Wave I $(n=20,745), 23 \%$ of respondents $(n=4,807)$ self-identify as Black or African-American. $79 \%$ of all eligible Add Health respondents participated in the initial survey (Wave I). 88.6\%, 77.4\%, and $80.3 \%$ of these respondents were reinterviewed in Waves II, III, and IV, respectively. Corresponding response rates for Black participants were $88.3 \%, 74.8 \%$, and $80.5 \%$.

For the current study, we used data from Waves I, III and IV to estimate the association between HBCU attendance and subsequent health in adulthood among African-Americans. HBCU attendance was assessed at Wave III (2001) when respondents were 18-26 years, while health was captured at Wave IV (2008) when respondents were 24-34 years. Sociodemographic 
characteristics concerning one's family of origin and early life exposures were measured at Wave I (1995) when respondents were between the ages of 12 and 19.

Add Health respondents interviewed at Wave I and enrolled in an institution of higher learning at Wave III were eligible to have information from the Integrated Postsecondary Education Data System (IPEDS) incorporated as part of the Adolescent Health and Academic Achievement (AHAA) supplement. ${ }^{30}$ Of the 5,487 Add Health respondents who report attending college at Wave III, 4,703 provided information to obtain high school transcripts, 4,171 supplied a valid institutional identifier for college, and 4,157 had IPEDS data successfully linked. Corresponding numbers for Black respondents were 1,214, 967, 848, and 842, respectively. Of the 842 Black Add Health participants with linked IPEDS data, 727 had valid information on dependent variables of interest. It is this subset of respondents who comprise the analytic sample of the current study. Sensitivity analyses revealed that our final sample $(n=727)$ did not significantly differ from the 842 Black college enrollees with linked IPEDS data or the 1,214 Black respondents who reported attending college at Wave III.

One of the AHAA questions indicated whether the respondent's postsecondary institution was an HBCU. Thus, this variable captures the current as opposed to the degree granting university. The National Center for Education Statistics (NCES), which produces IPEDS data, defines HBCUs as " ... institutions that were established prior to 1964 with the principal mission of educating Black Americans. ${ }^{31}$ " Based on this information, we constructed a dichotomous measure to capture enrollment in an HBCU vs. a PWI. Respondents in our sample attended a total of 319 institutions of higher learning, with 273 and 46 of them being PWIs and HBCUs, respectively. 
To capture health at Wave IV, we constructed an indicator of metabolic syndrome similar to Gaydosh and colleagues. ${ }^{32}$ We assessed whether respondents were above a high-risk threshold on five common biomarkers of cardiovascular health: blood pressure, waist circumference, triglycerides, high-density lipoprotein, and hemoglobin A1c (HbA1c) levels. Additional information regarding these high-risk thresholds can be found in Web Table 1. We defined metabolic syndrome as having three or more high-risk biomarkers. Participants with missing values on a biomarker were coded as low-risk for that variable; therefore, our results represent conservative estimates of the association between $\mathrm{HBCU}$ enrollment and metabolic syndrome. Sensitivity analyses conducted with respondents who had complete data on all metabolic syndrome indicators $(\mathrm{n}=599)$ produced similar findings.

We controlled for a number of potential confounders, all of which were captured at Wave I when respondents were in grades 7-12 unless otherwise specified. These included age (continuous), sex (male vs. female), census region (Northeast, Midwest, South, West), and urbanicity (urban, suburban, rural). To account for important institutional differences between HBCUs and PWIs, we included an indicator of public vs. private college. We were not able to further disaggregate for-profit institutions due to small cell sizes. Although the AHAA supplement does not have reliable information concerning college-specific graduation rates, we adjusted for the differential likelihood of college completion across HBCU status using a dichotomous indicator coded as 1 if the respondent graduated from college by Wave IV and 0 if he/she did not. We captured the respondent's baseline health status using the following three variables: obesity (yes/no); diabetes diagnosis (yes/no); and fair/poor self-rated health (yes/no). We incorporated additional control variables, all of which were multi-item measures, at Wave I to capture early life socioeconomic disadvantage at the family, school. and neighborhood 
levels. We assessed childhood family disadvantage using the following dichotomous indicators asked of the reporting parent: neither parent attended college, neither parent was employed in a skilled blue-collar or white-collar occupation, family welfare receipt, and parents not married. We assigned respondents a value of 1 for each affirmative answer and a value of 0 for each negative answer. School disadvantage indicators included grade retention rate, drop-out rate, average class size, proportion of teachers without graduate degrees as well as the proportion of students whose families received public assistance, parent(s) were unemployed, parent(s) did not finish high school, and parent(s) were unmarried. Neighborhood disadvantage measures were based on the census tract of residence and captured the proportion families below poverty, adults without high school degree, female headed households, vacant households, and the unemployment rate. We assigned respondents a value of 1 (high disadvantage) or 0 (low disadvantage) if their school or neighborhood fell within the top quartile of values among the full Add Health Wave I sample.

We estimated a series of logistic regression models to determine the extent to which HBCU attendance was associated with metabolic syndrome in adulthood. We regressed the probability of metabolic syndrome on HBCU enrollment and a number of potential confounders:

$$
\operatorname{logit}[\operatorname{Pr}(m s)]=\beta_{0}+\beta_{1} H B C U+\gamma \mathbf{x}
$$

where $\mathbf{x}$ represents a vector of additional covariates including age, sex, census region, urbanicity, private vs. public college, college graduation, baseline health status as well as family, school, and neighborhood disadvantage. To determine if the association between $\mathrm{HBCU}$ attendance and metabolic syndrome significantly differed for respondents who grew up in more segregated environments, we generated two interaction terms (HBCUdschool \% Black and HBCUdneighborhood \% Black), each of which was entered into the following regression model separately: 


$$
\operatorname{logit}[\operatorname{Pr}(m s)]=\beta_{0}+\beta_{1} H B C U+\beta_{2} \% \text { Black }+\beta_{3}(H B C U * \% \text { Black })+\gamma \mathbf{x}
$$

where $\mathbf{x}$ represents a vector of the same set of additional covariates. Robust standard errors were calculated using the Huber/White correction and clustered at the school level.

Regression models were estimated without sampling weights since (1) our research questions are specific to a distinct subgroup of respondents - college educated Blacks - and should not be generalized to a nationally representative population of U.S. adolescents and (2) applying sampling weights to small, demographically distinct subsamples can introduce bias into regression estimates. ${ }^{33}$ Missing values for covariates were calculated using multiple imputation methods with chained equations. Following Von Hippel, we did not impute values for dependent variables of interest since doing so adds little in efficiency and can create biased estimates. ${ }^{34}$ None of the control variables exceeded 5\% missing and most fell below $1 \%$ missing.

\section{RESULTS}

Descriptive findings are presented in Table 1. Almost $30 \%$ of respondents have metabolic syndrome at Wave IV. This result is remarkable since Add Health participants are still relatively young (24-34 years) and speaks to the health burden that college-educated African-Americans face despite their relatively high socioeconomic status. The distribution of metabolic syndrome across institutions of higher learning is not equivalent, with $31 \%$ of PWI attendees but only $23 \%$ of HBCU attendees having this condition.

We also note important differences across HBCU status in the types of educational and neighborhood environments Black Add Health respondents spent time in during their teenage years. PWI enrollees went to high schools that were, on average, $34 \%$ Black, while their counterparts at HBCUs attended high schools that were, on average, 57\% Black. Similarly, respondents at PWIs grew up in neighborhoods that were significantly less segregated (47\% 
Black) than respondents at HBCUs (59\% Black). Despite a greater likelihood of HBCU attendees to grow up in predominantly Black neighborhoods, we failed to find significant differences across HBCU status on two of the three measures of family disadvantage. Additional descriptive statistics for control variables are presented in Table 1. Furthermore, individual indicators, with corresponding descriptives, used to construct our measures of family, school, and neighborhood disadvantage are presented in Web Table 2.

Results from logistic regression models are presented in Table 2. Model 1 reveals the bivariate association between HBCU attendance and metabolic syndrome. HBCU enrollees faced $32 \%$ lower odds of developing metabolic syndrome compared to PWI enrollees. After controlling for all potential confounders, the magnitude of the odds ratio remains remarkably consistent and even becomes slightly more as opposed to less pronounced. Attending an HBCU vs. a PWI is associated with a $35 \%$ reduction in the odds of having metabolic syndrome net of the effect of key covariates (Model 7).

We used results from logistic regression models with interaction terms (HBCU\% Black), found in Web Table 3 to calculate the average marginal effects of HBCU attendance on the predicted probability of metabolic syndrome across levels of school (Figure 1) or neighborhood (Figure 2) segregation. Percentile Black is shown on the $\mathrm{x}$ axis, while the difference in the probability of metabolic syndrome between HBCU and PWI enrollees is displayed on the y axis. For Black respondents who attended predominantly White high schools $\left(5^{\text {th }}\right.$ percentile), those enrolled in either HBCUs or PWIs were similarly likely to develop metabolic syndrome (Figure 1). The health protective effect of HBCU attendance becomes more evident as the proportion of Black students in a given high school increases, although the magnitude of this change is modest and does not reach statistical significance. HBCU enrollees who attended integrated (50th 
percentile) or predominantly Black (95th percentile) high schools were 8.1 and 12.5 percentage points less likely to develop metabolic syndrome than PWI enrollees, respectively.

A similar, and more pronounced, trend whereby the association between $\mathrm{HBCU}$ enrollment and health is more evident at higher levels of segregation can be seen in Figure 2. Black Add Health respondents who grew up in predominantly White $\left(5^{\text {th }}\right.$ percentile) neighborhoods were similarly likely to develop metabolic syndrome regardless of the type of college attended. The opposite is true for HBCU enrollees who lived in integrated $\left(50^{\text {th }}\right.$ percentile) or predominantly Black $\left(95^{\text {th }}\right.$ percentile) neighborhoods. For these respondents, matriculating at an $\mathrm{HBCU}$ vs. a PWI was associated with a 7.5 and 16.4 percentage point reduction in the risk of metabolic syndrome, respectively.

\section{DISCUSSION}

Our empirical findings suggest that in addition to providing African-Americans a unique setting in which to pursue a college degree and serving as a driver of upward mobility, HBCUs offer Black students important, long-term health benefits. We report that African-Americans who attend HBCUs were significantly less likely than those at PWIs to develop metabolic syndrome in adulthood. The magnitude of this health benefit is similar to those reported in the literature following comprehensive lifestyle changes concerning diet and exercise. ${ }^{35}$ This finding is also notable since metabolic syndrome is a precursor to heart disease and stroke - two chronic diseases that account for a substantial proportion of mortality in the U.S. as well as serve as key drivers of racial disparities in health. ${ }^{36}$ Given the underlying pathophysiological mechanisms that link exposures to race-related stressors to suboptimal health outcomes primarily via the relentless 
triggering of the human stress response, ${ }^{37}$ we expect the potential health benefits of $\mathrm{HBCU}$ attendance to not be limited to this one outcome.

Unfortunately, we cannot discern why enrolling in an HBCU was associated with a lower risk of metabolic syndrome for African-Americans, but we can hypothesize. The health benefits of HBCU attendance might stem from an educational environment that (1) more effectively shields students from exposure to racial discrimination; (2) allows African-American college students to focus on learning and academic mastery while avoiding race-related stressors that have been linked to poor health outcomes, such as tokenism ${ }^{10}$ and hypervigilance, ${ }^{38}$ or (3) provides ample access to same-race mentors who have successfully navigated predominantly white environments in pursuit of educational or occupational advancement. Exploring how discrimination might mediate the association between $\mathrm{HBCU}$ attendance and health is important since, unlike other racial/ethnic groups, African-Americans continue to experience face discrimination even as they experience upward socioeconomic mobility ${ }^{5}$ and the health impacts of discrimination are likely to reverberate over time, both within and across generations. ${ }^{39,40}$

One of the most consequential findings of the current study is that the association between HBCU attendance and health appears to operate differently for those who grew up in more or less segregated environments. We note that the difference in the probability of metabolic syndrome was most pronounced for $\mathrm{HBCU}$ enrollees who went to predominantly Black high schools or lived in predominantly Black neighborhoods. Due to data constraints, we cannot identify the underlying mechanisms that produced this pattern, but these results suggests that HBCUs are likely to be health protective for the segment of society who needs it most -those growing up in the most racially isolated environments. Moreover, this finding underscores the important role that place, in general, and segregation, specifically, plays in the unequal 
distribution of health and that its influence gives rise to health disparities not only between races but also among members of a single race. ${ }^{22,41}$

Our results should be considered in light of several shortcomings. First, our analytic sample is small and limits the amount of statistical power available to detect differential health outcomes by HBCU status. Second, not all Add Health respondents who attended college at Wave III had valid, linked IPEDS data as part of the AHAA supplement, thus it remains to be seen if our results are generalizable to all African-American college students. However, sensitivity analyses did not reveal significant differences between these two subsamples. Third, although we were able to follow respondents into adulthood, we do not know if/how their health fluctuates as they move through successive lifecourse stages. Fourth, although we control for potential confounders, doing so cannot fully account for unobserved heterogeneity between HBCU and PWI enrollees. Prior research has shown that African-Americans from disadvantaged backgrounds with lower levels of school achievement are more likely to attend HBCUs; ${ }^{11}$ therefore, our results might be conservative estimates of the true association between $\mathrm{HBCU}$ enrollment and health. Finally, we wanted to further disaggregate analyses by sex, but could not do so with much precision due to our limited sample size. We look to future research to examine if the association between HBCU enrollment and health differs for men and women.

In order to gain a deeper understanding of how racial inequalities in health shape the life chances of racial minorities in the United States, researchers should stop treating AfricanAmericans as a monolithic group and start examining important differences among them. The current study sought to do this by (1) focusing on differential health outcomes among collegeeducated Blacks and (2) asking if the specific context in which higher education occurs has lasting health benefits. We find that for African-Americans, attending an $\mathrm{HBCU}$ as opposed to a 
PWI reduces the risk of developing metabolic syndrome by adulthood, particularly for individuals who grew up in segregated environments. These results lend credence to the idea that it is not just the information that is conveyed within a classroom setting that makes education a valuable social resource able to influence multiple outcomes, including health. To this end, policy makers should consider the full range of benefits that HBCUs are likely to have on the health and wellbeing of their students, both upon graduation and as they move through subsequent phases of their lives, as well as recognize them as a force for change in combatting racial inequalities in health. 


\section{References}

1. National Center for Health Statistics. Health, United States, 2017: With Special Feature on Mortality. Hyattsville, MD: National Center for Health Statistics; 2018.

2. Melvin J, Hummer RA, Elo IT, Mehta N. Age patterns of racial/ethnic/nativity differences in disability and physical functioning in the United States. Demogr Res. 2014;31(17):497510 .

3. Williams DR, Priest N, Anderson NB. Understanding associations among race, socioeconomic status, and health: Patterns and prospects. Health Psychol Off J Div Health Psychol Am Psychol Assoc. 2016;35(4):407-411.

4. Geronimus AT, Pearson JA, Linnenbringer E, et al. Race-Ethnicity, Poverty, Urban Stressors, and Telomere Length in a Detroit Community-based Sample. J Health Soc Behav. 2015;56(2):199-224.

5. Colen CG, Ramey DM, Cooksey EC, Williams DR. Racial disparities in health among nonpoor African Americans and Hispanics: The role of acute and chronic discrimination. Soc Sci Med. 2018;199:167-180.

6. Phelan JC, Link BG, Tehranifar P. Social conditions as fundamental causes of health inequalities: theory, evidence, and policy implications. J Health Soc Behav. 2010;51 Suppl:S28-40.

7. Mirowsky J, Ross CE. Education, Social Status, and Health. New York: Aldine de Gruyter; 2003.

8. Walsemann KM, Gee GC, Ro A. Educational attainment in the context of social inequality: New directions for research on education and health. Am Behav Sci. 2013;57(8):1082-1104.

9. Greer TM, Brown P. Minority status stress and coping processes among African American college students. J Divers High Educ. 2011;4(1):26-38.

10. Jackson PB, Saunders T. Work Stress, Coping Resources, and Mental Health: A Study of America's Black Elite. Res Occup Stress Well Being. 2006;5:139-169.

11. Kim MM, Conrad CF. The Impact of Historically Black Colleges and Universities on the Academic Success of African-American Students. Res High Educ. 2006;47(4):399-427.

12. Price GN, Spriggs W, Swinton OH. The Relative Returns to Graduating from a Historically Black College/University: Propensity Score Matching Estimates from the National Survey of Black Americans. Rev Black Polit Econ. 2011;38(2):103-130.

13. Fryer Jr. RG, Greenstone M. The Changing Consequences of Attending Historically Black Colleges and Universities. Am Econ J Appl Econ. 2010;2(1):116-148. 
14. Hall NM, Peterson J, Johnson M. To Test or Not to Test: Barriers and Solutions to Testing African American College Students for HIV at a Historically Black College/University. $J$ Health Disparities Res Pract. 2014;7(1):2.

15. Younge SN, Corneille MA, Lyde M, Cannady J. The paradox of risk: historically black college/university students and sexual health. J Am Coll Health J ACH. 2013;61(5):254262.

16. Barry AE, Jackson Z, Watkins DC, Goodwill JR, Hunte HER. Alcohol Use and Mental Health Conditions Among Black College Males: Do Those Attending Postsecondary Minority Institutions Fare Better Than Those at Primarily White Institutions? Am J Mens Health. 2017;11(4):962-968.

17. Watkins DC, Green BL, Goodson P, Guidry J, Stanley C. Using Focus Groups to Explore the Stressful Life Events of Black College Men. J Coll Stud Dev. 2007;48(1):105-118.

18. Gilbert SC, So D, Russell TM, Wessel TR. Racial Identity and Psychological Symptoms Among African Americans Attending a Historically Black University. J Coll Couns. 2006;9(2):111-122.

19. Elder GH, Johnson MK, Crosnoe R. The Emergence and Development of Life Course Theory. In: Mortimer JT, Shanahan MJ, eds. Handbook of the Life Course. Handbooks of Sociology and Social Research. Springer US; 2003:3-19.

20. Mollborn S, Lawrence E. Family, Peer, and School Influences on Children's Developing Health Lifestyles. J Health Soc Behav. 2018;59(1):133-150.

21. Benson JE, Elder Jr. GH. Young adult identities and their pathways: A developmental and life course model. Dev Psychol. 2011;47(6):1646-1657.

22. Williams DR, Collins C. Racial Residential Segregation: A Fundamental Cause of Racial Disparities in Health. Public Health Rep. 2001;116(5):404-416.

23. Osypuk TL, Acevedo-Garcia D. Beyond Individual Neighborhoods: A Geography of Opportunity Perspective for Understanding Racial/Ethnic Health Disparities. Health Place. 2010;16(6):1113-1123.

24. Borrell LN, Kiefe CI, Diez-Roux AV, Williams DR, Gordon-Larsen P. Racial discrimination, racial/ethnic segregation, and health behaviors in the CARDIA study. Ethn Health. 2013;18(3):227-243.

25. Kershaw KN, Diez Roux AV, Burgard SA, Lisabeth LD, Mujahid MS, Schulz AJ. Metropolitan-Level Racial Residential Segregation and Black-White Disparities in Hypertension. Am J Epidemiol. 2011;174(5):537-545.

26. Gee GC, Walsemann KM, Brondolo E. A Life Course Perspective on How Racism May Be Related to Health Inequities. Am J Public Health. 2012;102(5):967-974. 
27. Phelan JC, Link BG. Is Racism a Fundamental Cause of Inequalities in Health? Annu Rev Sociol. 2015;41(1):311-330.

28. Logan JR, Minca E, Adar S. The Geography of Inequality: Why Separate Means Unequal in American Public Schools. Sociol Educ. 2012;85.

29. Reardon SF, Fox L, Townsend J. Neighborhood Income Composition by Household Race and Income, 1990-2009. Ann Am Acad Pol Soc Sci. 2015;660(1):78-97.

30. Riegle-Crumb C, Chandra M, Grodsky E, Langenkamp AG, Pearson J. National Longitudinal Study of Adolescent Health Wave III Education Data: Postsecondary Contextual Component Codebook. Carolina Population Center, University of North Carolina; 2008.

31. U.S. Department of Education, National Center for Education Statistics. Historically Black Colleges and Universities. https://nces.ed.gov/fastfacts/display.asp?id=667. Accessed January 19, 2020.

32. Gaydosh L, Schorpp KM, Chen E, Miller GE, Harris KM. College completion predicts lower depression but higher metabolic syndrome among disadvantaged minorities in young adulthood. Proc Natl Acad Sci. 2018;115(1):109-114.

33. Winship C, Radbill L. Sampling Weights and Regression Analysis. Sociol Methods Res. 1994;23(2):230-257.

34. Hippel PTV. Regression with Missing Ys: An Improved Strategy for Analyzing Multiply Imputed Data. Sociol Methodol. 2007;37(1):83-117.

35. Yamaoka K, Tango T. Effects of lifestyle modification on metabolic syndrome: a systematic review and meta-analysis. BMC Med. 2012;10(1):138.

36. Riddell CA, Morrison KT, Kaufman JS, Harper S. Trends in the contribution of major causes of death to the black-white life expectancy gap by US state. Health Place. 2018;52:85-100.

37. Goosby BJ, Cheadle JE, Mitchell C. Stress-Related Biosocial Mechanisms of Discrimination and African American Health Inequities. Annu Rev Sociol. 2018;44(1):319340 .

38. Hicken MT, Lee H, Morenoff J, House JS, Williams DR. Racial/ethnic disparities in hypertension prevalence: reconsidering the role of chronic stress. Am J Public Health. 2014;104(1):117-123.

39. Novak NL, Geronimus AT, Martinez-Cardoso AM. Change in birth outcomes among infants born to Latina mothers after a major immigration raid. Int J Epidemiol. 2017;46(3):839-849. 
40. Gee G, Walsemann K. Does health predict the reporting of racial discrimination or do reports of discrimination predict health? Findings from the National Longitudinal Study of Youth. Soc Sci Med. 2009;68(9):1676-1684.

41. LaVeist T, Pollack K, Thorpe R, Fesahazion R, Gaskin D. Place, not race: disparities dissipate in southwest Baltimore when blacks and whites live under similar conditions. Health Aff Proj Hope. 2011;30(10):1880-1887. 
Table 1. Descriptive Statistics for College Educated African-American Add Health Respondents, Full Sample and by HBCU/PWI Attendance ${ }^{\mathrm{a}, \mathrm{b}}$

\begin{tabular}{|c|c|c|c|c|c|c|c|}
\hline \multirow[b]{2}{*}{ Variables } & \multicolumn{2}{|c|}{ Full Sample (727) } & \multicolumn{2}{|r|}{ PWI (551) } & \multicolumn{2}{|r|}{ HBCU (176) } & \multirow{2}{*}{$\begin{array}{l}t \text { Statistic for } \\
\text { Difference }\end{array}$} \\
\hline & $\%$ & Mean and Std Dev & $\%$ & Mean and Std Dev & $\%$ & Mean and Std Dev & \\
\hline Metabolic syndrome & 0.29 & & 0.31 & & 0.23 & & $-1.93^{c}$ \\
\hline HBCU attendance & 0.32 & & & & & & \\
\hline School \% Black & & $0.39(0.27)$ & & $0.34(0.24)$ & & $0.57(0.28)$ & $10.81^{\mathrm{f}}$ \\
\hline Neighborhood \% Black & & $0.50(0.34)$ & & $0.47(0.34)$ & & $0.59(0.32)$ & $4.31^{\mathrm{f}}$ \\
\hline Age & & $14.95(1.69)$ & & $15.08(1.67)$ & & $14.53(1.66)$ & $-3.75^{\mathrm{f}}$ \\
\hline Female & 0.64 & & 0.66 & & 0.58 & & $-1.95^{\mathrm{c}}$ \\
\hline \multicolumn{8}{|l|}{ Region } \\
\hline Northeast & 0.14 & & 0.16 & & 0.05 & & $-3.59^{f}$ \\
\hline Midwest & 0.22 & & 0.21 & & 0.28 & & $2.20^{\mathrm{d}}$ \\
\hline South & 0.19 & & 0.23 & & 0.03 & & $-5.89^{f}$ \\
\hline West & 0.45 & & 0.40 & & 0.64 & & $5.17^{\mathrm{f}}$ \\
\hline \multicolumn{8}{|l|}{ Urbanicity } \\
\hline Urban & 0.53 & & 0.52 & & 0.57 & & 1.25 \\
\hline Suburban & 0.28 & & 0.30 & & 0.22 & & $-2.14^{\mathrm{d}}$ \\
\hline Rural & 0.19 & & 0.18 & & 0.21 & & 0.85 \\
\hline Private (vs. public) college & 0.21 & & 0.18 & & 0.30 & & $3.52^{\mathrm{f}}$ \\
\hline Graduated college & 0.57 & & 0.54 & & 0.68 & & $3.38^{\mathrm{f}}$ \\
\hline \multicolumn{8}{|l|}{ Childhood disadvantage } \\
\hline Family & & $1.27(0.95)$ & & $1.31(0.98)$ & & $1.13(0.86)$ & $-2.20^{\mathrm{d}}$ \\
\hline School & & $2.77(1.93)$ & & $2.75(1.92)$ & & $2.85(1.96)$ & 0.58 \\
\hline Neighborhood & & $2.08(1.90)$ & & $1.92(1.87)$ & & $2.57(1.91)$ & $4.12^{\mathrm{f}}$ \\
\hline \multicolumn{8}{|l|}{ Childhood health } \\
\hline Obesity & 0.18 & & 0.18 & & 0.16 & & -0.31 \\
\hline Diabetes & 0.09 & & 0.10 & & 0.09 & & 0.00 \\
\hline \multicolumn{8}{|l|}{ Self-rated health } \\
\hline Excellent & 0.33 & & 0.34 & & 0.32 & & -0.34 \\
\hline Very good & 0.40 & & 0.40 & & 0.39 & & -0.17 \\
\hline Good & 0.20 & & 0.19 & & 0.23 & & 1.39 \\
\hline Fair or poor & 0.07 & & 0.08 & & 0.05 & & -1.21 \\
\hline
\end{tabular}

${ }^{a}$ Historically Black College or University (HBCU); Predominately White institution (PWI).

${ }^{b}$ National Longitudinal Survey of Adolescent to Adult Health (Add Health), Waves I, III, and IV (1994-2009). Descriptive statistics generated using imputed values for covariates.

${ }^{\mathrm{c}} \mathrm{p}<.1 ;{ }^{\mathrm{d}} \mathrm{p}<.05 ;{ }^{\mathrm{e}} \mathrm{p}<.01 ;{ }^{\mathrm{f}} \mathrm{p}<.001 ;$ two-tailed tests. 
Table 2. Odds Ratios and 95\% Confidence Intervals from Logistic Regression Analyses Predicting the Probability of Metabolic Syndrome at Wave 4 among Black Add Health Respondents ${ }^{\mathrm{a}, \mathrm{b}}$

\begin{tabular}{|c|c|c|c|c|c|c|c|c|c|c|c|c|c|c|}
\hline \multirow{2}{*}{$\begin{array}{l}\text { Independent Variables } \\
\text { HBCU attendance }\end{array}$} & \multicolumn{2}{|c|}{$\begin{array}{l}\text { Model } 1 \text { (727) } \\
\text { OR and 95\% CI }\end{array}$} & \multicolumn{2}{|c|}{$\begin{array}{l}\text { Model } 2(727) \\
\text { OR and 95\% CI }\end{array}$} & \multicolumn{2}{|c|}{$\begin{array}{l}\text { Model } 3 \text { (727) } \\
\text { OR and 95\% CI }\end{array}$} & \multicolumn{2}{|c|}{$\begin{array}{l}\text { Model } 4 \text { (727) } \\
\text { OR and 95\% CI }\end{array}$} & \multicolumn{2}{|c|}{$\begin{array}{l}\text { Model } 5 \text { (727) } \\
\text { OR and 95\% CI }\end{array}$} & \multicolumn{2}{|c|}{$\begin{array}{l}\text { Model } 6 \text { (727) } \\
\text { OR and 95\% CI }\end{array}$} & \multicolumn{2}{|c|}{$\begin{array}{l}\text { Model } 7 \text { (727) } \\
\text { OR and 95\% CI }\end{array}$} \\
\hline & $0.68^{\mathrm{d}}$ & $0.47,0.99$ & $0.6^{\mathrm{e}}$ & $0.42,0.88$ & $0.63^{\mathrm{d}}$ & $0.44,0.91$ & $0.64^{\mathrm{d}}$ & $0.44,0.93$ & $0.63^{\mathrm{d}}$ & $0.44,0.89$ & $0.63^{\mathrm{d}}$ & $0.45,0.90$ & $0.65^{\mathrm{d}}$ & $0.45,0.94$ \\
\hline Age & & & 1.01 & $0.91,1.09$ & 1.00 & $0.91,1.09$ & 1.00 & $0.91,1.09$ & 0.98 & $0.90,1.08$ & 0.97 & $0.89,1.07$ & 0.98 & $0.89,1.07$ \\
\hline Female & & & 0.91 & $0.67,1.24$ & 0.93 & $0.68,1.26$ & 0.92 & $0.68,1.25$ & 0.91 & $0.67,1.23$ & 0.93 & $0.68,1.26$ & 0.94 & $0.66,1.35$ \\
\hline \multicolumn{15}{|l|}{ Census Region } \\
\hline Northeast & & & 1.00 & Referent & 1.00 & Referent & 1.00 & Referent & 1.00 & Referent & 1.00 & Referent & 1.00 & Referent \\
\hline Midwest & & & $0.53^{\mathrm{d}}$ & $0.30,0.94$ & $0.54^{\mathrm{d}}$ & $0.31,0.93$ & $0.54^{\mathrm{d}}$ & $0.31,0.92$ & $0.57^{d}$ & $0.34,0.94$ & $0.56^{\mathrm{d}}$ & $0.34,0.93$ & 0.64 & $0.38,1.09$ \\
\hline South & & & 0.81 & $0.50,1.29$ & 0.81 & $0.51,1.28$ & 0.81 & $0.51,1.29$ & 0.82 & $0.52,1.29$ & 0.82 & $0.52,1.30$ & 0.86 & $0.54,1.38$ \\
\hline West & & & 0.75 & $0.52,1.08$ & 0.76 & $0.52,1.10$ & 0.77 & $0.53,1.11$ & $0.75^{\mathrm{c}}$ & $0.55,1.03$ & $0.68^{\mathrm{d}}$ & $0.47,0.97$ & $0.7^{\mathrm{c}}$ & $0.50,1.00$ \\
\hline \multicolumn{15}{|l|}{ Urbanicity } \\
\hline Urban & & & 1.00 & Referent & 1.00 & Referent & 1.00 & Referent & 1.00 & Referent & 1.00 & Referent & 1.00 & Referent \\
\hline Suburban & & & 0.96 & $0.62,1.49$ & 0.95 & $0.61,1.48$ & 0.96 & $0.62,1.48$ & 0.98 & $0.64,1.48$ & 0.93 & $0.61,1.42$ & 1.01 & $0.65,1.55$ \\
\hline Rural & & & 0.93 & $0.60,1.43$ & 0.93 & $0.61,1.43$ & 0.92 & $0.60,1.42$ & 0.92 & $0.60,1.43$ & 0.93 & $0.60,1.43$ & 0.91 & $0.59,1.41$ \\
\hline $\begin{array}{l}\text { Private (vs. public) } \\
\text { college }\end{array}$ & & & & & 1.19 & $0.83,1.71$ & 1.18 & $0.82,1.70$ & 1.16 & $0.81,1.68$ & 1.14 & $0.79,1.65$ & 1.20 & $0.82,1.75$ \\
\hline Graduated college & & & & & $0.65^{\mathrm{d}}$ & $0.47,0.92$ & $0.67^{\mathrm{d}}$ & $0.47,0.95$ & $0.68^{\mathrm{d}}$ & $0.48,0.97$ & $0.68^{\mathrm{d}}$ & $0.48,0.96$ & $0.70^{\mathrm{d}}$ & $0.50,0.98$ \\
\hline Family disadvantage & & & & & & & 1.07 & $0.87,1.30$ & 1.05 & $0.86,1.28$ & 1.06 & $0.86,1.29$ & 1.06 & $0.87,1.29$ \\
\hline School disadvantage & & & & & & & & & 1.06 & $0.99,1.15$ & $1.08^{\mathrm{c}}$ & $1.00,1.17$ & 1.07 & $0.98,1.16$ \\
\hline $\begin{array}{l}\text { Neighborhood } \\
\text { disadvantage }\end{array}$ & & & & & & & & & & & 0.94 & $0.85,1.03$ & 0.94 & $0.85,1.03$ \\
\hline \multicolumn{15}{|l|}{ Childhood health } \\
\hline Obesity & & & & & & & & & & & & & $2.47^{\mathrm{f}}$ & $1.47,4.16$ \\
\hline Diabetes & & & & & & & & & & & & & 1.30 & $0.59,2.88$ \\
\hline Self-rated health & & & & & & & & & & & & & 0.98 & $0.82,1.17$ \\
\hline
\end{tabular}

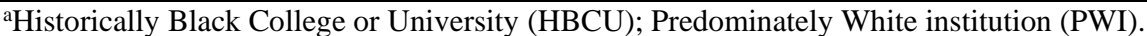

${ }^{b}$ National Longitudinal Survey of Adolescent to Adult Health (Add Health), Waves I, III, and IV (1994-2009).

${ }^{\mathrm{c}} \mathrm{p}<.1 ;{ }^{\mathrm{d}} \mathrm{p}<.05 ;{ }^{\mathrm{e}} \mathrm{p}<.01 ;{ }^{\mathrm{f}} \mathrm{p}<.001 ;$ two-tailed tests. 


\section{FIGURES}

Figure 1. Average Marginal Effects of HBCU Attendance on Probability of Metabolic Syndrome by Percentiles of School Racial Concentration.

Source: National Longitudinal Survey of Adolescent to Adult Health, Wave IV (2008-2009). Historically Black College or University (HBCU), predominately White institution (PWI) 


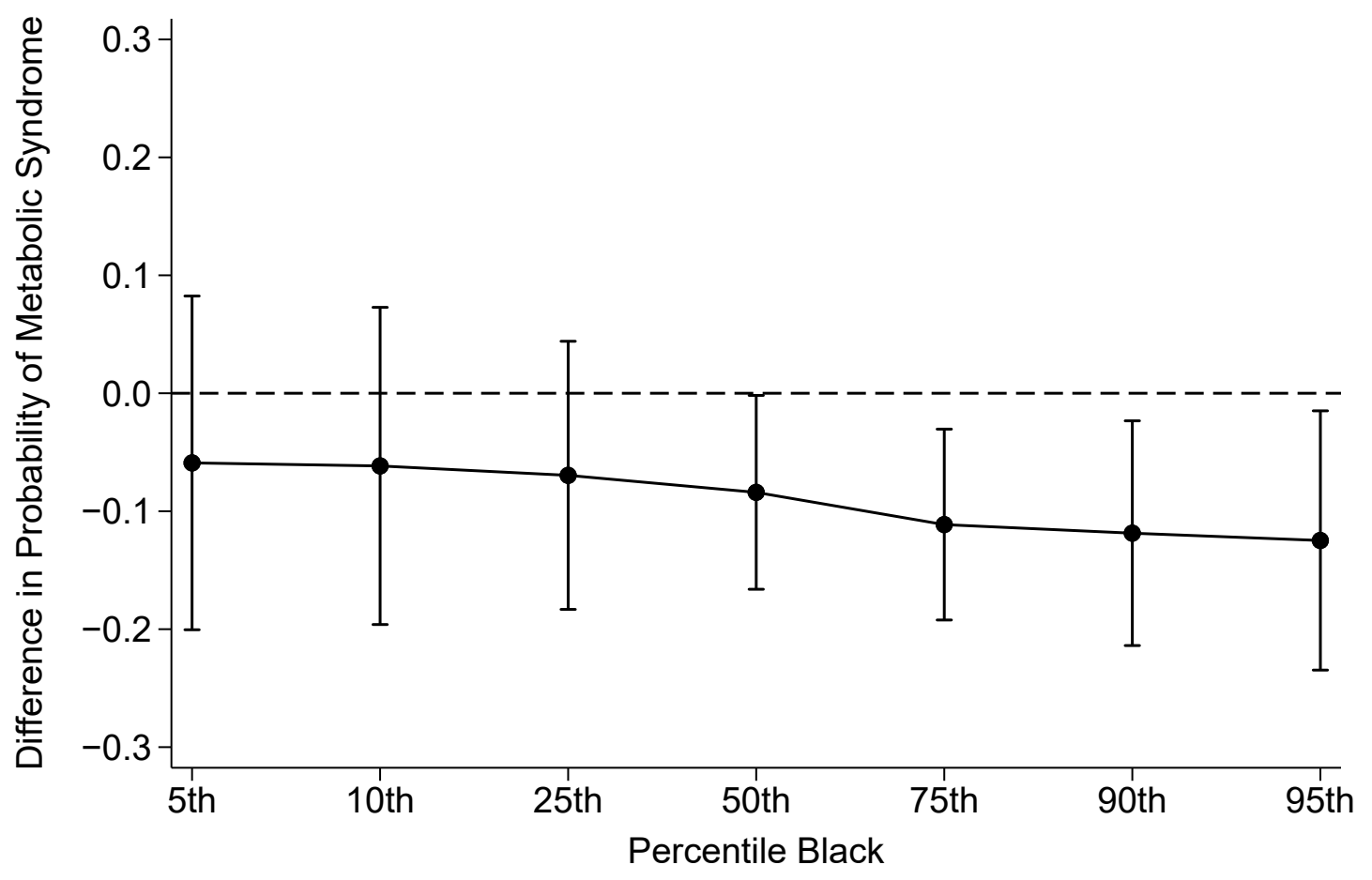


Figure 2. Average Marginal Effects of HBCU Attendance on Probability of Metabolic Syndrome by Percentiles of Neighborhood Racial Concentration.

Source: National Longitudinal Survey of Adolescent to Adult Health, Wave IV (2008-2009). Historically Black College or University (HBCU), predominately White institution (PWI). 


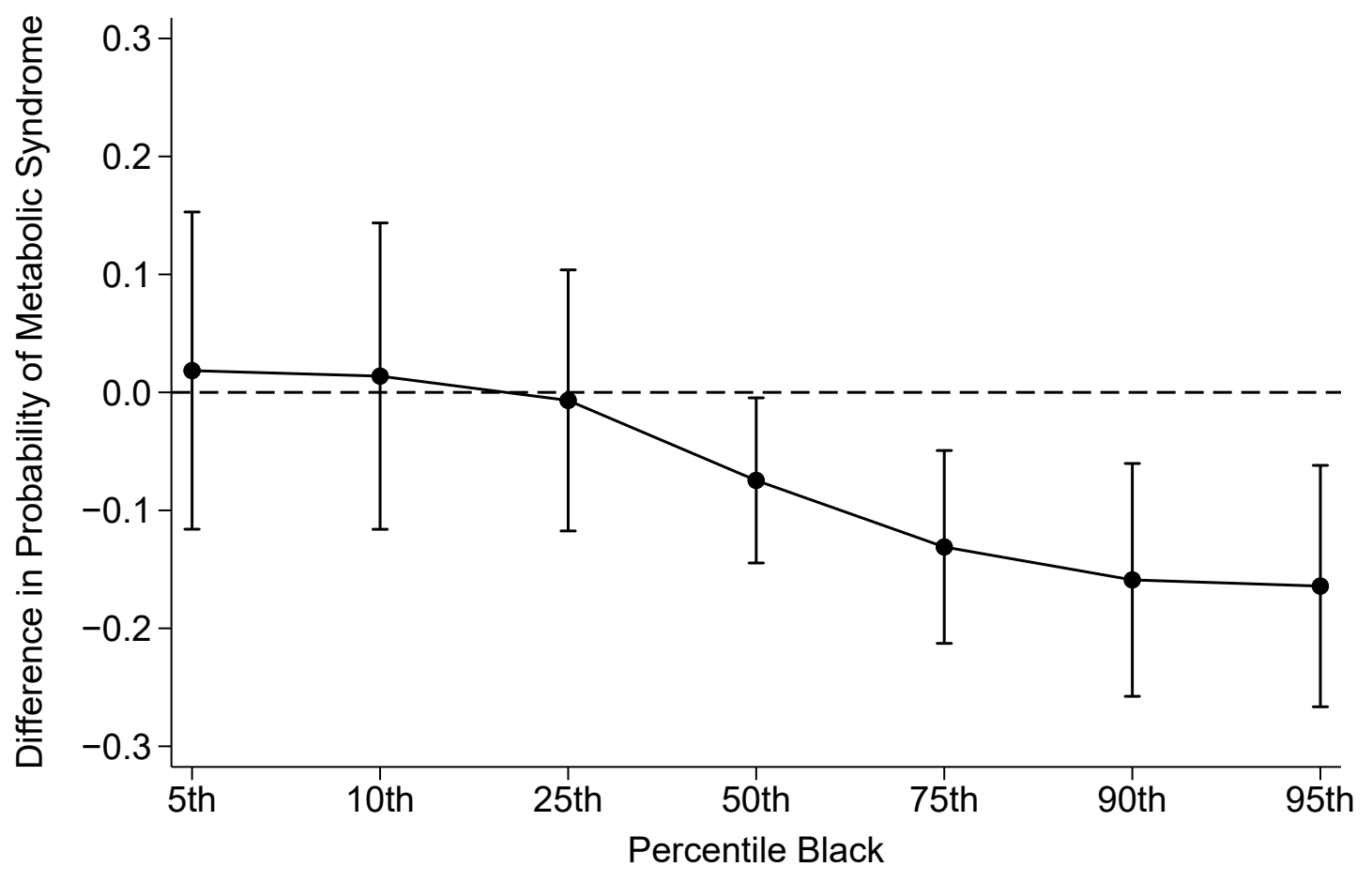




\section{Racial Disparities in Health among College Educated African-Americans: Can HBCU Attendance Reduce the Risk of Metabolic Syndrome in Midlife?}

Cynthia G. Colen, Nicolo P. Pinchak, and Kierra S. Barnett

\section{Web Material}

Web Table 1. Biomarkers with Corresponding High Risk Thresholds Used to Create Metabolic Syndrome Outcome Measure

Web Table 2. Regression Results Predicting the Log Odds of Metabolic Syndrome by Neighborhood or School Racial Composition at Wave IV among Black Add Health Respondents

Web Table 3. Descriptive Statistics for Individual Measures that Comprise Family, School, and Neighborhood Disadvantage Indices, Full Sample and by HBCU/PWI Attendance 
Web Table 1. Biomarkers with Corresponding High Risk Thresholds Used to Create Metabolic Syndrome Outcome Measure

Outcome Variable

Hypertension

Waist Circumference

Triglycerides

High Density Lipoproteins (HDL)

HbA1c Levels
High Risk Threshold

$\mathrm{BP}>130 / 85 \mathrm{mmHg}$

Diagnosed with hypertension

Currently taking antihypertensive medication

Greater than $102 \mathrm{~cm}$ for men or $88 \mathrm{~cm}$ for women

Top 3 deciles for men or top 2 deciles for women

Bottom 2 deciles for men or bottom 3 deciles for women

At or above $5.7 \%$ hemoglobin A1c 
Web Table 2. Descriptive Statistics for Individual Measures that Comprise Family, School, and Neighborhood Disadvantage Indices, Full Sample and by HBCU/PWI Attendance

\begin{tabular}{|c|c|c|c|c|c|c|}
\hline Mean & $\begin{array}{c}\text { Std. } \\
\text { Dev. }\end{array}$ & Mean & $\begin{array}{l}\text { Std. } \\
\text { Dev. }\end{array}$ & Mean & $\begin{array}{l}\text { Std. } \\
\text { Dev. }\end{array}$ & $\begin{array}{l}t \text { Statistic } \\
\text { for }\end{array}$ \\
\hline \multicolumn{2}{|c|}{ Full Sample } & \multicolumn{2}{|c|}{ PWI } & \multicolumn{2}{|c|}{$\mathrm{HBCU}$} & Difference \\
\hline
\end{tabular}

\begin{tabular}{|c|c|c|c|c|c|c|c|}
\hline \multicolumn{8}{|l|}{ Family disadvantage } \\
\hline Parents no college & 0.39 & 0.49 & 0.40 & 0.49 & 0.34 & 0.47 & -1.61 \\
\hline Parents low status occupation(s) & 0.17 & 0.38 & 0.19 & 0.39 & 0.12 & 0.33 & $-2.08^{*}$ \\
\hline Family welfare receipt & 0.22 & 0.41 & 0.25 & 0.43 & 0.14 & 0.35 & $-2.88^{* *}$ \\
\hline Parents not married & 0.49 & 0.50 & 0.48 & 0.50 & 0.53 & 0.50 & 1.31 \\
\hline \multicolumn{8}{|l|}{ School disadvantage } \\
\hline Grade retention rate & 0.39 & 0.49 & 0.41 & 0.49 & 0.35 & 0.48 & -1.41 \\
\hline Drop out rate & 0.41 & 0.49 & 0.44 & 0.50 & 0.33 & 0.47 & $-2.50^{*}$ \\
\hline Number students per class & 0.27 & 0.44 & 0.30 & 0.46 & 0.18 & 0.39 & $-3.08^{* * *}$ \\
\hline Teachers w/ graduate degree & 0.27 & 0.44 & 0.28 & 0.45 & 0.22 & 0.41 & $-1.82^{\dagger}$ \\
\hline Students on public assistance & 0.22 & 0.41 & 0.21 & 0.41 & 0.24 & 0.43 & 0.94 \\
\hline Students w/ unemployed parents & 0.34 & 0.47 & 0.32 & 0.47 & 0.41 & 0.49 & $2.28^{*}$ \\
\hline Students w/ parents did not graduate HS & 0.37 & 0.48 & 0.37 & 0.48 & 0.40 & 0.49 & 0.74 \\
\hline Students w/ unmarried parents & 0.49 & 0.50 & 0.42 & 0.49 & 0.72 & 0.45 & $7.08^{* * *}$ \\
\hline \multicolumn{8}{|l|}{ Neighborhood disadvantage } \\
\hline Families below poverty & 0.43 & 0.50 & 0.39 & 0.49 & 0.55 & 0.50 & $3.82^{* * * *}$ \\
\hline Adults without HS degree & 0.35 & 0.48 & 0.35 & 0.48 & 0.36 & 0.48 & 0.48 \\
\hline Female headed households & 0.52 & 0.50 & 0.48 & 0.50 & 0.65 & 0.48 & $4.11^{* * * *}$ \\
\hline Vacant houses & 0.32 & 0.47 & 0.28 & 0.45 & 0.45 & 0.50 & $4.41^{* * *}$ \\
\hline Unemployment rate & 0.46 & 0.50 & 0.42 & 0.49 & 0.55 & 0.50 & $3.10^{* *}$ \\
\hline $\mathrm{N}$ & \multicolumn{2}{|c|}{727} & \multicolumn{2}{|c|}{551} & \multicolumn{2}{|c|}{176} & \\
\hline
\end{tabular}

Source: National Longitudinal Survey of Adolescent Health, Waves I, III, and IV.

Note: All variables are displayed as proportions.

${ }^{\dagger} \mathrm{p}<.1 ;{ }^{*} \mathrm{p}<.05 ;{ }^{* *} \mathrm{p}<.01 ;{ }^{* * *} \mathrm{p}<.001 ;$ two-tailed tests. 
Web Table 3. Regression Results Predicting the Log Odds of Metabolic Syndrome by Neighborhood or School Racial Composition at Wave IV among Black Add Health Respondents

$\begin{array}{lllll}\text { Model } 1 & \text { Model } 2 & \text { Model } 3 & \text { Model } 4 & \text { Model } 5\end{array}$

HBCU attendance

$\begin{array}{lllll}-0.43 * & -0.51^{*} & -0.46^{*} & -0.44^{*} & -0.40^{*} \\ (0.19) & (0.21) & (0.24) & (0.20) & (0.20)\end{array}$

School \% Black

$0.11 \quad 0.14$

$(0.08) \quad(0.10)$

HBCU*School \% Black

$-0.10$

$(0.20)$

Neighborhood \% Black

$0.04 \quad 0.11$

$(0.13) \quad(0.13)$

HBCU*Neighborhood \% Black

$-0.37 *$

$(0.18)$

$\mathrm{N}$

727

727

727

727

727

Source: National Longitudinal Survey of Adolescent Health, Waves I, III, and IV.

Notes: All models control for respondent's age, sex, census region, urbanicity, private/public college, graduation, early life disadvantage (family, school, and neighborhood), and childhood health (obesity, diabetes, self-rated health). Clustered robust standard errors are in parentheses.

${ }^{\dagger} \mathrm{p}<.1 ;{ }^{*} \mathrm{p}<.05 ;{ }^{* *} \mathrm{p}<.01 ;{ }^{* * *} \mathrm{p}<.001 ;$ two-tailed tests. 